\title{
SMALL BASELINE SUBSET (SBAS) PIXEL DENSITY VS. GEOLOGY AND LAND USE IN SEMI-ARID REGIONS IN SYRIA
}

\author{
Deodato Tapete ${ }^{(a, b)}$, Francesca Cigna ${ }^{(b)}$, Andrew Sowter $^{(c)}$, Stuart Marsh ${ }^{(c)}$ \\ ${ }^{a}$ Department of Geography, Institute of Hazard Risk and Resilience, Durham University, UK \\ ${ }^{b}$ British Geological Survey, Natural Environment Research Council, UK

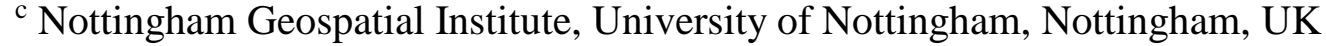

\begin{abstract}
36 ENVISAT ASAR images acquired in 2002 to 2010 along descending passes with nominal revisiting time of 35 days were processed over the whole region of Homs, western Syria, by implementing the low-pass Small Baseline Subset (SBAS) technique. More than 280,000 coherent pixels with $\sim 100 \mathrm{~m}$ ground resolution were obtained. We analysed pixel spatial distribution in respect of local geology and land use, to assess to what extent these factors can influence the performance of an interferometric deformation analysis in a semi-arid environment. Filtering out the amount of pixels associated with the urban fabric of Homs and surrounding villages, it is apparent that limestone and marl units are less prone to generate coherent pixels if compared with the basalt units in the north-western sector of the processed region. The latter resulted in pixel density of $\sim 50-60$ pixels $/ \mathrm{km}^{2}$, which is comparable with that found over urban settlements and man-made structures.
\end{abstract}

Index Terms - Small BAseline Subset (SBAS), pixel density, land use, land cover, geology, Syria

\section{INTRODUCTION}

Recent Interferometric Synthetic Aperture Radar (InSAR) studies demonstrated that the measurement density of monitoring targets retrievable from techniques of Persistent Scatterers can be predicted against land cover and local topography [1-3]. Major benefit of this type of assessment is the possibility to understand a priori whether the processing of the area of interest will result in sufficient grids of monitoring points to use for the deformation analysis, and therefore whether the acquisition of SAR data stacks and their InSAR processing are worth being undertaken.

This paper aims to discuss the pixel density distribution observed across the city of Homs and the surrounding region, in western Syria, by processing ENVISAT ASAR descending mode imagery (2002-2010) with Small Baseline Subset (SBAS) techniques [4], and to investigate the relationship between pixel density and local geology and land use. The nature and morphology of the areas of bare soil and rock outcrop appear to play a key role in the identification of coherent radar targets, in some cases to the extent that these land cover can generate pixel densities comparable with those over urban settlements and manmade structures.

\section{STUDY AREA, INPUT DATA AND SBAS PROCESSING}

We investigated an area of $\sim 9,000 \mathrm{~km}^{2}$ surrounding Homs town which can be broadly divided into two main regions with different dominant geology and land use (Figure 1a; [cf. 5,6]). The north-western basalt area consists of a series of low ridges, alluvial valleys and depressions that range in elevation between $400-600 \mathrm{~m}$ a.s.l. and is defined by the edge of the River Orontes to the east and the Homs Lake (i.e. Lake Qattina) to the south (Figure 1); the whole area is characterized by inherent stoniness and denudation of tree cover. Conversely, the southern region of Homs is dominated by flat marl landscapes predominate, with irrigated fields that spread radially from the Orontes.

With regard to bedrock geology we used the geological map of Syria, at 1:200,000 scale (Figure 1a; [5,6]), while updated information of land cover and land use was extracted by using time series of Landsat imagery and GoogleEarth of contemporary temporal coverage with ENVISAT ASAR imagery.

36 ENVISAT ASAR descending images acquired between 31/12/2002 and 31/08/2010 along track 307 with nominal 35-day repeat cycle were processed by implementing the low-pass SBAS technique [4].

After precise co-registration, a subset centred at $36.8^{\circ} \mathrm{E}$, $34.7^{\circ} \mathrm{N}$ was selected. Multi-looking was undertaken using factors of 20 and 4 in azimuth and range respectively, and $\sim 100 \mathrm{~m}$ ground resolution pixels were obtained. 136 small baseline differential interferograms were computed using perpendicular baseline threshold of $200 \mathrm{~m}$, temporal baselines less than 4 years and pixel coherence threshold of 0.25 . The subsequent processing steps were undertaken according to the conventional low-pass SBAS [4]. 


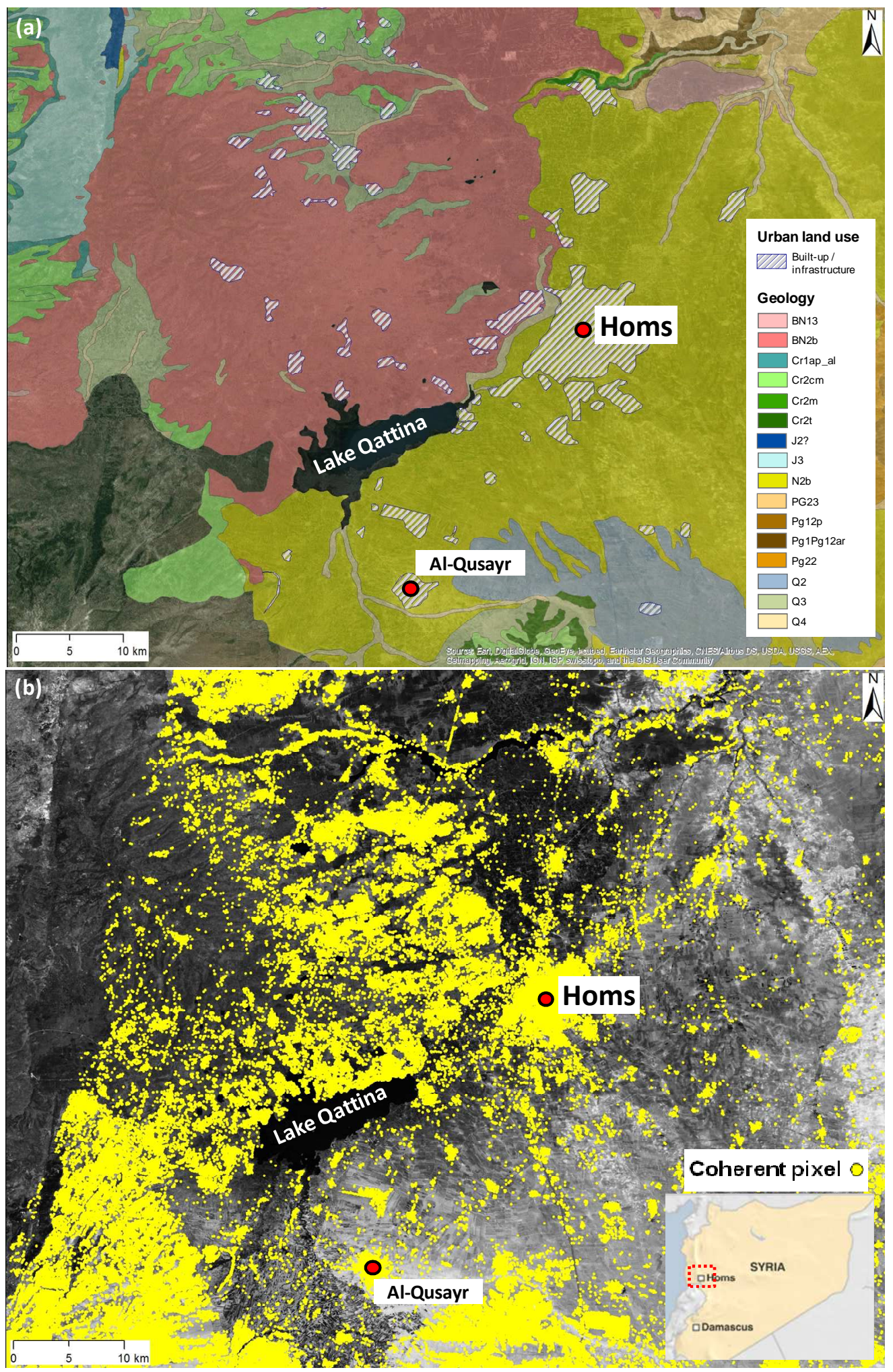

Figure 1. (a) Geological map 1:200,000 scale of the region of Homs, western Syria (modified from Ponikarov [5,6] to which the reader should refer for detailed description of the geological units), overlapped onto World Imagery mosaic accessed via ArcGIS Online. The major urban settlements, towns and infrastructure are reported. (b) Spatial distribution of the coherent pixels obtained from low-pass SBAS processing of ENVISAT descending data (2002-2010), overlapped onto Landsat mosaic (2005). 


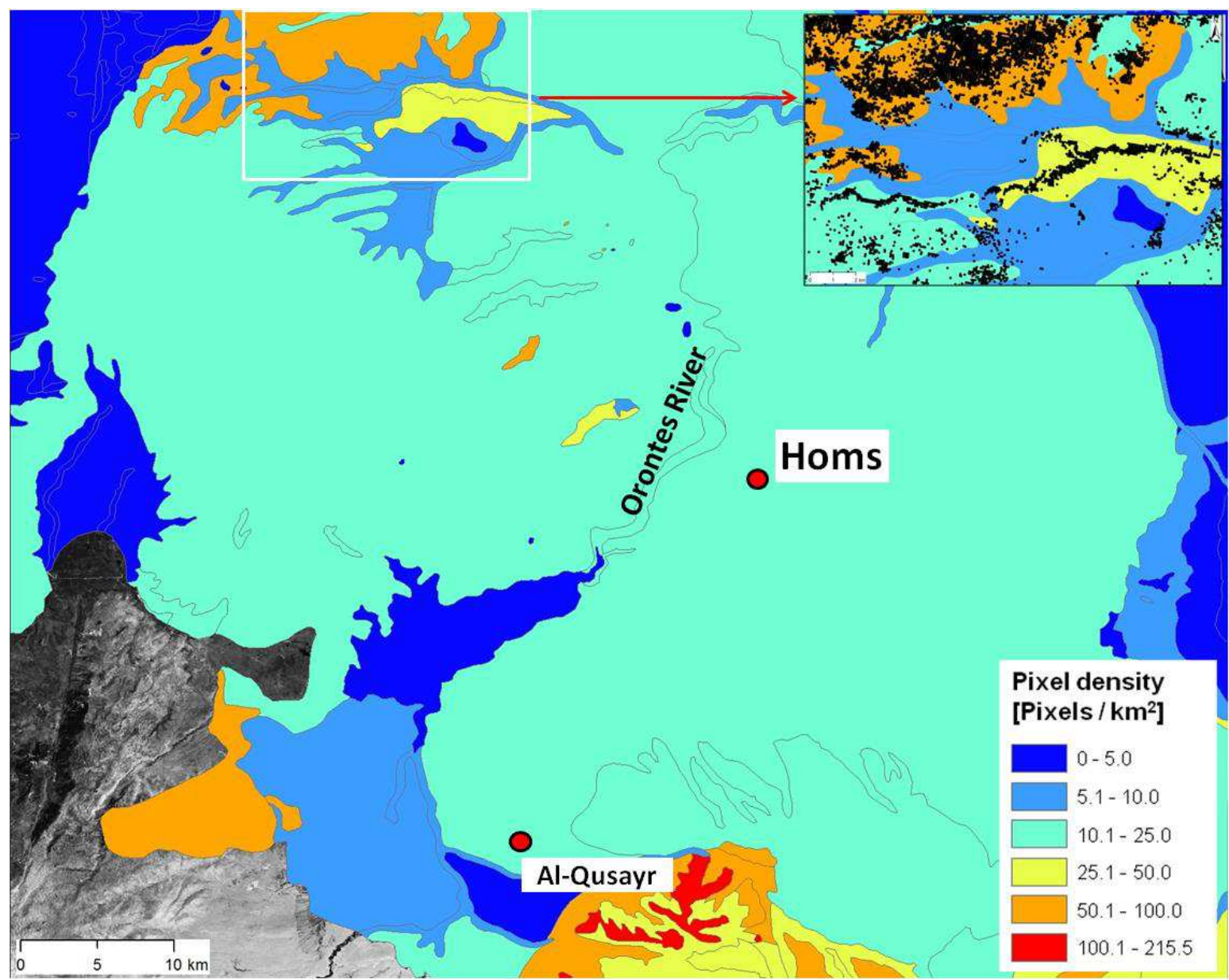

Figure 2. SBAS pixel density calculated against local geology (cf. Figure la) with zoomed view of differential distribution of coherent pixels (black dots; cf. Figure 1b) across neighbouring lithologies (see inset on top right corner).

\section{SBAS RESULTS AND DISCUSSION}

Figure $1 \mathrm{~b}$ shows the spatial distribution of the coherent pixels identified (more than 280,000). As expected, higher pixel densities are located over the urban settlements and infrastructure (cf. Figure 1a), the highest of which is found for Homs town, followed by the villages in the outskirtsand those spread across the whole region, such as Al-Qusayr located about $10 \mathrm{~km}$ south of the SW edge of Lake Qattina.

Statistics including pixel density were calculated against the geological units, and results are shown in Figure 2. More than $2,530 \mathrm{~km}^{2}$ of the total area corresponding with the Pliocene basalt region NW of the Orontes, Homs and the southern limestone and marls valleys, are covered by moderately dense pixel coverage (see cyan polygons in Figure 2), i.e. 10 to 25 pixels $/ \mathrm{km}^{2}$. Although at a glance this seem a satisfactory result, it is to be noted that, specifically for the area of Homs and the geological unit of Pliocene limestones and marls (i.e. N2b in Figure 1a), a significant proportion of the retrieved coherent pixels is associated with urban structures instead of bare soil or natural features (cf.
Figure 1a-b). Taking into account the built environment of Homs over an area of $\sim 87 \mathrm{~km}^{2}$, SBAS processing identified more than 5,400 pixels, meaning $\sim 62$ pixels $/ \mathrm{km}^{2}$. Hence, when the urban radar targets are excluded from the computation, a limited density of coherent pixels are found over the Pliocene limestones and marls.

Conversely, the pixel density statistics mark very clearly some lithologies with high coverage of monitoring solutions (Figure 2). In this regard we observe, for instance, two areas of Cretaceous Cenomanian dolomites, limestones, marls and basalts (cf. geological unit $\mathrm{Cr} 2 \mathrm{~cm}$ in Figure 1a) located along the northern edge of the processed area (see inset in Figure 2) and to the south-west close to the borders with Lebanon (bottom left corner in Figure 2). The pixel density reaches here $\sim 53$ and 65 pixels $/ \mathrm{km}^{2}$ respectively, i.e. values comparable with the above mentioned pixel density over Homs town, whic make these two areas considerably more populated by measurement points than the neighbouring lithologies.

In light of these results obtained with the conventional SBAS technique, tests are being carried out with the recently 
developed Intermittent Small Baseline Subset (ISBAS) method [7] that has already proven valuable to increase the pixel density across any land cover type and enable better zonation of deformation patterns [8]. Comparison between the spatial distribution obtained from the conventional SBAS and ISBAS is being undertaken to verify if ISBAS can improve the suitability for radar target identification of those lithologies in the region of Homs that were found poorly covered by SBAS solutions. In this regard, the scarcity of man-made structures and predominance of bare to cultivated soil in these areas serve as a means of understanding whether the geological setting has a beneficial or detrimental effect on the identification of monitoring targets.

\section{CONCLUSIONS}

Our analysis of the pixel spatial distribution retrieved from regional-scale SBAS processing clearly shows the different behaviour of the two dominant lithologies in the region of Homs. Filtering out pixels associated with the urban fabric of Homs and surrounding villages, it is apparent that limestone and marl units are less prone to generate coherent pixels than the basalt units in the north-west. This finding reveals an effect of local geology and its surface morphology on the identification of coherent pixels selected during the SBAS chain.

The impact of this type of research is two-fold. A priori assessment of the suitability of the different lithologies and land cover types to generate SBAS pixels allows us to anticipate reliably the performance achievable with the interferometric processing over certain classes of land cover/land use and geology units.

Such a comprehensive picture of the pixel spatial distribution can be also used as a baseline environment characterization to compare with pixel densities from SBAS processing of newly acquired satellite time series. With specific regard to Syria, this type of analysis might support studies of landscape changes not only due to environmental impacts of natural processes, but also of anthropogenic alteration during conflicts [9].

\section{ACKNOWLEDGEMENTS}

This research was led by Dr D. Tapete, supported by a European Union COFUND/Durham Junior Research Fellowship [under EU grant agreement no. 267209].

ENVISAT ASAR data were made available by ESA via the Category-1 project Id.28439. World Imagery was accessed via ArcGIS Online.

\section{REFERENCES}

[1] F. Cigna, L.B. Bateson, C.J. Jordan, and C. Dashwood, "Simulating SAR geometric distortions and predicting Persistent Scatterer densities for ERS-1/2 and ENVISAT C-band SAR and InSAR applications: Nationwide feasibility assessment to monitor the landmass of Great Britain with SAR imagery," Remote Sensing of Environment, Elsevier, pp. 441-466, 2014.

[2] F. Cigna, A. Sowter, C.J. Jordan, and B.G. Rawlins, "Intermittent Small Baseline Subset (ISBAS) monitoring of land covers unfavourable for conventional C-band InSAR: proof-ofconcept for peatland environments in North Wales, UK," in Proc. SPIE 9243, SAR Image Analysis, Modeling, and Techniques XIV, Amsterdam, The Netherlands, 924305, 2014.

[3] S. Plank, J. Singer, and K. Thuro, “Assessment of number and distribution of persistent scatterers prior to radar acquisition using open access land cover and topographical data," ISPRS Journal of Photogrammetry and Remote Sensing, Elsevier, pp. 132-147, 2013.

[4] P. Berardino, G. Fornaro, R. Lanari, and E. Sansosti, "A new algorithm for surface deformation monitoring based on small baseline differential SAR interferograms," IEEE Transactions on Geoscience \& Remote Sensing, IEEE, pp. 2375-2383, 2002.

[5] Ponikarov, V. (Ed.), Geological Map of Syria (1: 1,000,000; 2nd Edition), Establishment of Geology and Mineral Resources (Ministry of Petroleum and Mineral Resources), Syrian Arab Republic, 1986.

[6] Ponikarov, V., V. Kozlov, A. Artemov, and A. Kalis, Geological map of Syria, 1:200,000 scale, sheet I-36-XVIII, I-37XIII, Homs-Trablus, Technoexport, Moscow, and Ministry of Industry, Damascus, 1963.

[7] A. Sowter, L. Bateson, P. Strange, K. Ambrose, and M. Syafiudin, "DInSAR estimation of land motion using intermittent coherence with application to the South Derbyshire and Leicestershire coalfield," Remote Sensing Letters, Taylor \& Francis, pp. 979-987, 2013.

[8] L. Bateson, F. Cigna, D. Boon, and A. Sowter, "The application of the Intermittent SBAS (ISBAS) InSAR method to the South Wales Coalfield, UK," International Journal of Applied Earth Observation and Geoinformation, Elsevier, pp. 249-257, 2015.

[9] D. Tapete, F. Cigna, D.N.M. Donoghue, and G. Philip, "Mapping changes and damages in areas of conflict: from archive C-band data to new HR X-band imagery, towards the Sentinels," FRINGE Workshop 2015, European Space Agency Special Publication ESA SP-731, European Space Agency, pp. 1-4, 2015. 